\title{
Involvement of Potassium Channels in Spinal Antinociceptions Induced by Fentanyl, Clonidine and Bethanechol in Rats
}

\author{
Isao Yamazumi*, Takahiko Okuda and Yoshihisa Koga \\ Department of Anesthesiology, Kinki University School of Medicine, 377-2, Ohno-Higashi, Osakasayama, Osaka 589-8511, Japan
}

Received July 10, 2001 Accepted September 18, 2001

\begin{abstract}
In the central nervous systems, intracellular and extracellular movement of potassium ions plays an important role in regulating neuronal excitability and the release of neurotransmitters. The purpose of our study was to determine whether nicorandil (adenosine triphosphate-sensitive $\mathrm{K}^{+}$channel opener) exerts antinociceptive effects by itself or in combination with fentanyl, clonidine and bethanechol and whether glibenclamide (adenosine triphosphate-sensitive $\mathrm{K}^{+}$channel blocker) and charybdotoxin $\left(\mathrm{Ca}^{2+}\right.$-activated $\mathrm{K}^{+}$channel blocker) may antagonize the antinociceptive action of fentanyl, clonidine and bethanechol. Antinociceptive effects were assessed using the tail-flick test in rats. Nicorandil (100 $\mu \mathrm{g})$ and antinociceptively ineffective doses of fentanyl $(1 \mu \mathrm{g})$, clonidine $(2.5 \mu \mathrm{g})$ or bethanechol $(10 \mu \mathrm{g})$ were coadministered intrathecally (i.t.). Glibenclamide $(100 \mu \mathrm{g})$ or charybdotoxin $(2.5 \mathrm{ng})$ were administered i.t. at $5 \mathrm{~min}$ before each effective dose of fentanyl $(2.5 \mu \mathrm{g})$, clonidine $(10 \mu \mathrm{g})$ or bethanechol $(40 \mu \mathrm{g})$. The present findings demonstrated that i.t. administration of nicorandil alone exerted no influence on the tail-flick latency. However, concomitant administrations of antinociceptively inactive doses of fentanyl, clonidine or bethanechol with nicorandil elicited significant suppression of the thermonociceptive response. Also, each antinociception induced by fentanyl, clonidine or bethanechol was partially antagonized by both glibenclamide and charybdotoxin. These findings showed that activation of the $\mathrm{K}^{+}$channel might enhance the antinociceptive effects of fentanyl, clonidine and bethanechol.
\end{abstract}

Keywords: Antinociception, $\mathrm{K}^{+}$channel, Fentanyl, Clonidine, Bethanechol

Recently, an increasing number of reports have been published about $\mathrm{K}^{+}$channels. It is noteworthy that $\mathrm{K}^{+}$ channels show diversity in structure, location, function, and response to drugs. For instance, there are several reports concerning myocardial protection of $\mathrm{K}^{+}$channels that indicate the association between this function and opioids (1), volatile anesthetics (2), venous anesthetics (3) and local anesthetics (4). $\mathrm{K}^{+}$channels also exist in mitochondria (5), pancreas (6), lung (7), skeletal muscle (8), vascular smooth muscle (9) and the central nervous system (10). Several kinds of $\mathrm{K}^{+}$channels with different electrophysiological characteristics and pharmacological sensitivities have been described in neurons $(10,11)$; in particular, adenosine triphosphate-sensitive $\mathrm{K}^{+}$channels $\left(\mathrm{K}^{+}{ }_{\text {ATP }}\right.$ channels) have been widely identified $(12,13)$. $\mathrm{K}_{\text {ATP }}^{+}$channels, located in pre- and postsynaptic neurons and belonging to one of the $\mathrm{K}^{+}$channel families, are characterized by their sensitivity to blockade by higher intra-

*Corresponding author. FAX: +81-723-66-0226

E-mail: isy@ma.neweb.ne.jp cellular concentrations of ATP (14). This channel activity is antagonized by $\mathrm{K}_{\text {ATP }}^{+}$channel blockers such as glibenclamide, gliquidone, glipizide and tolbutamide; and it is activated by $\mathrm{K}_{\text {ATP }}^{+}$channel openers such as nicorandil, cromakalim, levcromakalim, minoxidil, pinacidil and diazoxide.

Although it has been clarified that $\mathrm{K}^{+}$channels exist on spinal dorsal horn neurons $(10,15)$, such reports are limited when compared to those on myocardial cells. Moreover, the $\mathrm{K}^{+}$channel functions and responses to drugs in the central nervous system have not been clearly elucidated. Considering the modulatory effects of fentanyl ( $\mu$-opioid agonist), clonidine ( $\alpha_{2}$ adrenergic agonist) and bethanechol (muscarinic agonist) on spinal nociceptive transmission, it is of interest to investigate possible interactions between the respective drugs and $\mathrm{K}^{+}$channels.

The purpose of our study was to determine whether nicorandil (adenosine triphosphate-sensitive $\mathrm{K}^{+}$channel opener, $\mathrm{K}_{\text {ATP }}^{+}$channel opener) exerts antinociceptive effects by itself or in combination with fentanyl, clonidine and bethanechol and whether glibenclamide (adenosine 
triphosphate-sensitive $\mathrm{K}^{+}$channel blocker, $\mathrm{K}^{+}{ }_{\text {ATP }}$ channel blocker) and charybdotoxin $\left(\mathrm{Ca}^{2+}\right.$-activated $\mathrm{K}^{+}$channel blocker) may antagonize the antinociceptive action of fentanyl, clonidine and bethanechol by using the tail-flick test in rats.

\section{MATERIALS AND METHODS}

\section{Animal model}

The protocol was approved by our Institutional Animal Care Committee. Experiments were performed on 160 male Sprague-Dawley rats (Japan SLC, Inc., Hamamatsu), weighing $250-300 \mathrm{~g}$, housed in individual cages and given free access to water and food. Rats were anesthetized with $50 \mathrm{mg} / \mathrm{kg}$ (i.p.) sodium pentobarbital under spontaneous respiration. After a skin incision on the atlas and occipital bone, muscular tissue attached to the occipital bone was exfoliated to expose the process of the atlas. A minor incision was made carefully to the atlantooccipital membrane and dura mater avoiding damage to the spinal cord. Cerebrospinal fluid was removed by suction and a polyethylene catheter (Becton Dickinson Primary Care Diagnostics, Sparks, MD, USA) was introduced into the lumbar subarachnoid space (16). The catheter was advanced to a position $9 \mathrm{~cm}$ from the operated site such that its tip was located at the lumbar enlargement of the spinal cord. The dead space of the catheter was $10 \mu \mathrm{l}$. Appropriate catheter placement was confirmed by injecting $10 \mu \mathrm{l}$ of $2 \%$ lidocaine and subsequent flushing with $10 \mu \mathrm{l}$ physiological saline into the intrathecal space.

The position of the catheter tip was judged to be in the intrathecal space if paralysis and dragging of the hind limbs occurred within $30 \mathrm{~s}$ after intrathecal (i.t.) administration of lidocaine. Any rats exhibiting a motor activity deficit were eliminated from the study. A period of not less than 5 days was allowed for the animals to recover from surgery before the experiments.

\section{Antinociceptive assessment}

Antinociceptive effects were assessed using the tail-flick test (Tail Flick Unit 7360; Ugo Basile, Comerio, Italy). The tail was placed over a slit, through which heat (sensitivity 15) was focused, on the table of the device. The nociceptive latency was taken to be the time when the tail either flicked or moved away from the focused heat stimulus. The time interval from the onset of the heat stimulus to any flick or avoidance movement of the tail was recorded automatically by the mechanical device. To prevent tissue damage, the heat stimulus was cut off at $10 \mathrm{~s}$ if no response was triggered (cut-off time), and the cut-off time was then assigned as the response latency for the case tested.

Baseline tail-flick latencies were assessed and animals whose latencies were more than $5 \mathrm{~s}$ were omitted from the following experiments. In both per se and concomitant administrations, tail-flick latencies were taken 5, 15, 30, 60 and $90 \mathrm{~min}$ after i.t. administration. The latencies before and after i.t. administration were evaluated. The latencies were obtained with 6 consecutive trials and the last 2 trials were calculated as the mean value.

\section{Single-drug administration}

A $10-\mu 1$ syringe attached to one end of the catheter was used for i.t. administration. Drugs for i.t. administration were dissolved in $10 \mu \mathrm{l}$ of physiological saline. After each i.t. drug injection, the catheter was flushed by a subsequent $10-\mu 1$ volume of physiological saline to ensure that the drug was completely delivered to the spinal cord. Administration was performed over a period of $10 \mathrm{~s}$. Control trials were conducted with physiological saline. After determining the baseline tail-flick latencies, rats were treated i.t. with 1 and $2.5 \mu \mathrm{g}$ of fentanyl (Sankyo Co., Ltd., Tokyo), 2.5 and $10 \mu \mathrm{g}$ of clonidine (Sigma Chemical Co., Ltd., St. Louis, MO, USA), 10 and $40 \mu \mathrm{g}$ of bethanechol (Sigma Chemical Co., Ltd.), 100 and $200 \mu \mathrm{g}$ of nicorandil (Chugai Pharmaceutical Co., Ltd., Tokyo), $100 \mu \mathrm{g}$ of glibenclamide (Sigma Chemical Co., Ltd.) and $2.5 \mathrm{ng}$ of charybdotoxin (Sigma Chemical Co., Ltd.).

Maximum concentrations that had not induced any effect or antinociception in our pilot study were considered to be 'low-dose' of fentanyl, clonidine and bethanechol. Minimum concentrations that had completely exerted antinociceptive effects in our pilot study were considered to be 'high-dose' of fentanyl, clonidine and bethanechol. The maximum limit of nicorandil dissolved in $10 \mu \mathrm{l}$ of physiological saline was $200 \mu \mathrm{g}$, i.t.; administrations of doses larger than this induced total paralysis of the hind limbs in our pilot study. The doses of $\mathrm{K}^{+}$channel blocker used were calculated based on previous reports on mice (17). In this study on rats, the doses of glibenclamide and charybdotoxin were ten times larger than that on mice. Glibenclamide was dissolved in 2\% Tween 80 (Fisher Scientific Co., Fair Lawn, NJ, USA) because of its low solubility in physiological saline.

\section{Concomitant drug administration}

The $\mathrm{K}_{\text {ATP }}^{+}$channel opener nicorandil $(100 \mu \mathrm{g})$ and antinociceptively ineffective doses of fentanyl $(1 \mu \mathrm{g})$, clonidine $(2.5 \mu \mathrm{g})$ or bethanechol $(10 \mu \mathrm{g})$ were coadministered i.t. to assess the interaction with $10 \mu \mathrm{l}$ each of concomitant drug administration.

\section{Pretreatment drugs}

In animals administered i.t. with antinociceptively effective doses of fentanyl $(2.5 \mu \mathrm{g})$, clonidine $(10 \mu \mathrm{g})$ or bethanechol $(40 \mu \mathrm{g})$, the $\mathrm{K}_{\text {ATP }}^{+}$channel blocker glibenclamide $(100 \mu \mathrm{g})$ or the $\mathrm{Ca}^{2+}$-activated $\mathrm{K}^{+}$channel blocker 
charybdotoxin ( $2.5 \mathrm{ng}$ ) was similarly administered at $5 \mathrm{~min}$ before administration of each drug. Baseline tail-flick latencies were assessed before and after injecting the $\mathrm{K}^{+}$ channel blockers.

\section{Data analyses}

The tail-flick latency after the drug administration was converted to a percentage of the maximum possible effects $(\% \mathrm{MPE})$, where $\% \mathrm{MPE}=($ post-drug latency - baseline latency) / (cut-off time - baseline latency) $\times 100$. The means were compared, and differences between the values were verified with variance analysis (ANOVA). Differences in data compared to the control values were verified with the Mann-Whitney U-test, where $P<0.05$ was considered statistically significant.

\section{RESULTS}

Effects of $\mathrm{K}^{+}$channel openers and blockers on spinal antinociception

None of the single administrations of nicorandil (100 and $200 \mu \mathrm{g})$, glibenclamide $(100 \mu \mathrm{g})$, charybdotoxin $(2.5 \mathrm{ng})$, $2 \%$ Tween 80 and physiological saline showed any antinociceptive effect (data not shown).

\section{Effects of $\mathrm{K}^{+}$channels on fentanyl-induced antinociception}

Spinal antinociception was not observed in single administration of $1 \mu \mathrm{g}$ of fentanyl (low-dose). The tail-flick latencies were significantly higher than the baseline when nicorandil was concomitantly administered, with the $\%$ MPE value increasing to $78 \%$ and $54 \%$ at 5 and $15 \mathrm{~min}$ after drug administration, respectively $(P<0.05)$. The tailflick latency mostly returned to the baseline (2\%) at $60 \mathrm{~min}$ after concomitant drug administration (Fig. 1).

Spinal antinociception was observed in single admin- istration of $2.5 \mu \mathrm{g}$ of fentanyl (high-dose), and it was partially antagonized by pretreatment with $100 \mu \mathrm{g}$ of glibenclamide. The \%MPE was significantly $(P<0.05)$ suppressed from $100 \%$ to $59 \%$, from $99 \%$ to $38 \%$ and from $95 \%$ to $8 \%$ at 5,15 and 30 min after administration of high-dose fentanyl, respectively (Fig. 2).

Similarly, antinociception by high-dose fentanyl was partially antagonized by pretreatment with $2.5 \mathrm{ng}$ of charybdotoxin. The \%MPE was significantly $(P<0.05)$ decreased from $100 \%$ to $63 \%$, from $99 \%$ to $38 \%$ and from $95 \%$ to $15 \%$ at 5,15 and $30 \mathrm{~min}$ after administration of high-dose fentanyl, respectively (Fig. 2).

\section{Effects of $K^{+}$channels on clonidine-induced antinocicep- tion}

Although spinal antinociception was not observed in single administration of $2.5 \mu \mathrm{g}$ of clonidine (low-dose), an antinociceptive effect was elicited when nicorandil was concomitantly administered with low-dose clonidine. The $\%$ MPE was significantly elevated to $95 \%, 85 \%, 74 \%$ and $30 \%$ at $5,15,30$ and 60 min after administration, respectively $(P<0.05)$. The tail-flick latency was higher $(16 \%)$ than the baseline even at $90 \mathrm{~min}$ after concomitant drug administration (Fig. 3).

Spinal antinociception was observed in single administration of $10 \mu \mathrm{g}$ of clonidine (high-dose), and it was partially antagonized by pretreatment with $100 \mu \mathrm{g}$ of glibenclamide. The \%MPE was significantly $(P<0.05)$ suppressed from $90 \%$ to $39 \%$, from $99 \%$ to $19 \%$, from $98 \%$ to $12 \%$ and from $58 \%$ to $3 \%$ at $5,15,30$ and 60 min after i.t. administration of high-dose clonidine, respectively (Fig. 4).

Likewise, antinociception by high-dose clonidine was partially antagonized by pretreatment with $2.5 \mathrm{ng}$ of charybdotoxin. The \%MPE was significantly $(P<0.05)$

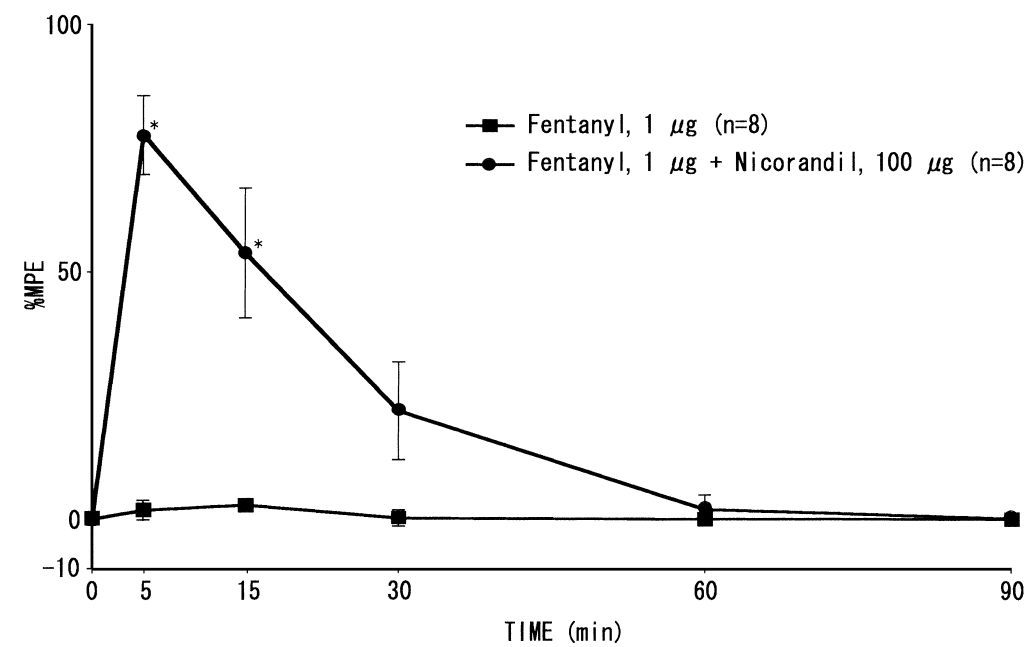

Fig. 1. Effects of concomitant administrations of fentanyl $(1 \mu \mathrm{g})$ and nicorandil $(100 \mu \mathrm{g})$ on the rat tail flick-latency. Although single intrathecal administrations of $1 \mu \mathrm{g}$ fentanyl (low-dose) did not affect the thermonociceptive response, significant antinociceptive effects were established with concomitant administrations of $1 \mu \mathrm{g}$ fentanyl (low-dose) and nicorandil. Post-administration tail-flick latencies were expressed as a percentage of the maximum possible effect (\%MPE). Values are each the mean \pm S.E.M. of 8 rats. Statistical significance $\left({ }^{*} P<0.05\right)$ was determined by comparison with the curve for $1 \mu \mathrm{g}$ fentanyl (closed squares). 


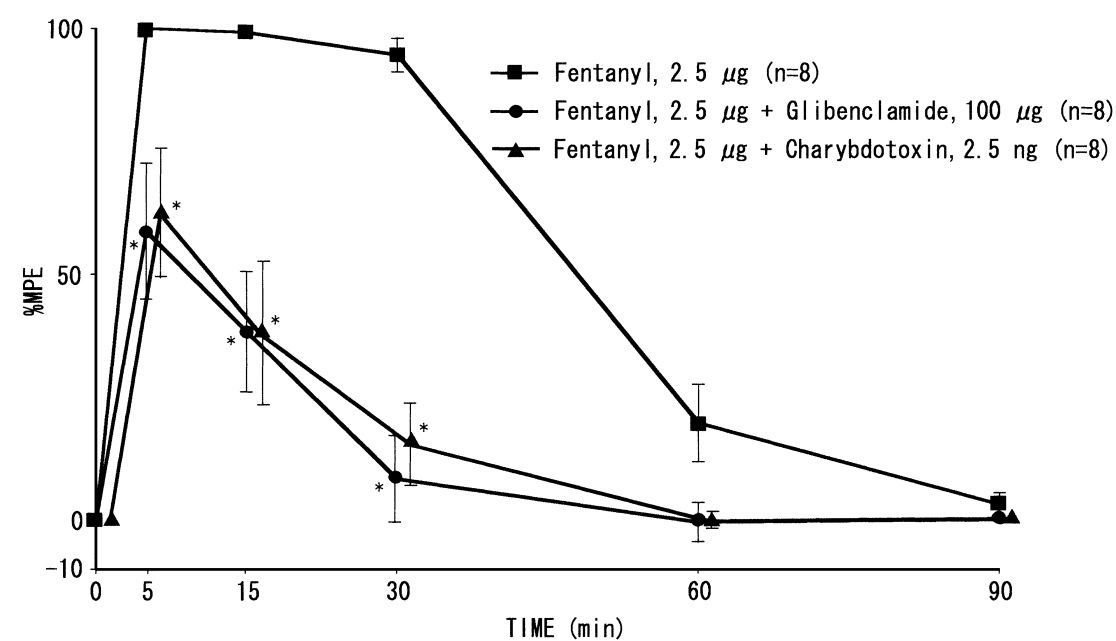

Fig. 2. Effects of pretreatment administrations of glibenclamide $(100 \mu \mathrm{g})$ or charybdotoxin $(2.5 \mathrm{ng})$ before fentanyl $(2.5 \mu \mathrm{g})$ on the rat tail-flick latency. Intrathecal administrations of $2.5 \mu \mathrm{g}$ fentanyl (high-dose) produced antinociceptive effects, and fentanyl (high-dose, $2.5 \mu \mathrm{g}$ )induced antinociception was partially blocked by both glibenclamide and charybdotoxin. Postadministration tail-flick latencies were expressed as a percentage of the maximum possible effect (\%MPE). Values are each the mean \pm S.E.M. of 8 rats. Statistical significance $(* P<0.05)$ was determined by comparison with the curve for $2.5 \mu \mathrm{g}$ fentanyl (closed squares).

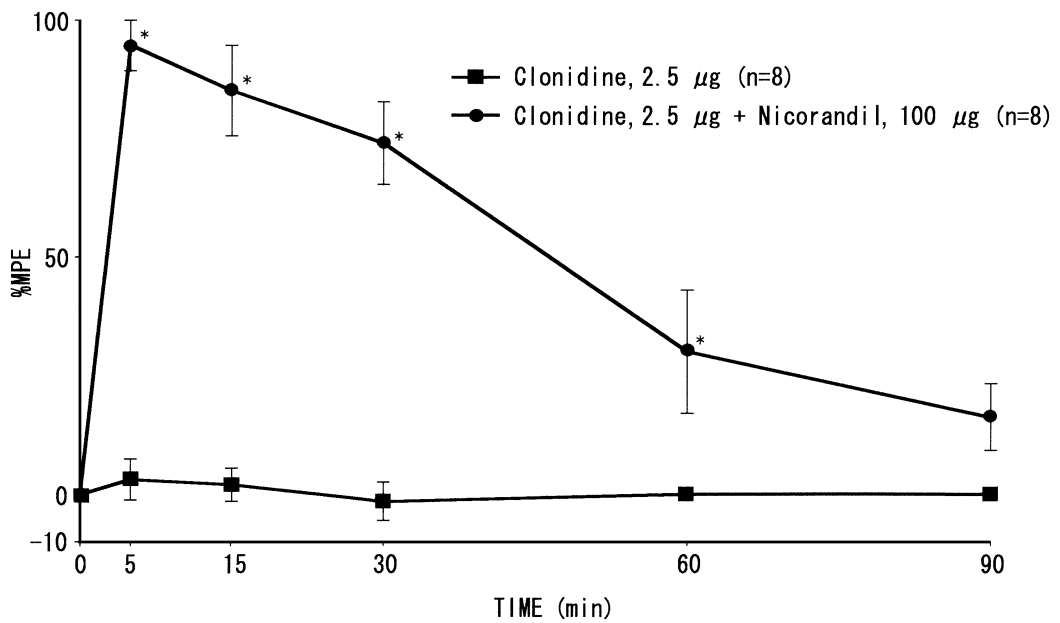

Fig. 3. Effects of concomitant administrations of clonidine $(2.5 \mu \mathrm{g})$ and nicorandil $(100 \mu \mathrm{g})$ on the rat tail-flick latency. Although single intrathecal administrations of $2.5 \mu \mathrm{g}$ clonidine (low-dose) did not affect the thermonociceptive response, significant antinociceptive effects were established with concomitant administrations of $2.5 \mu \mathrm{g}$ clonidine (lowdose) and nicorandil. Post-administration tail-flick latencies were expressed as a percentage of the maximum possible effect (\%MPE). Values are each the mean \pm S.E.M. of 8 rats. Statistical significance $(* P<0.05)$ was determined by comparison with the curve for $2.5 \mu \mathrm{g}$ clonidine (closed squares).

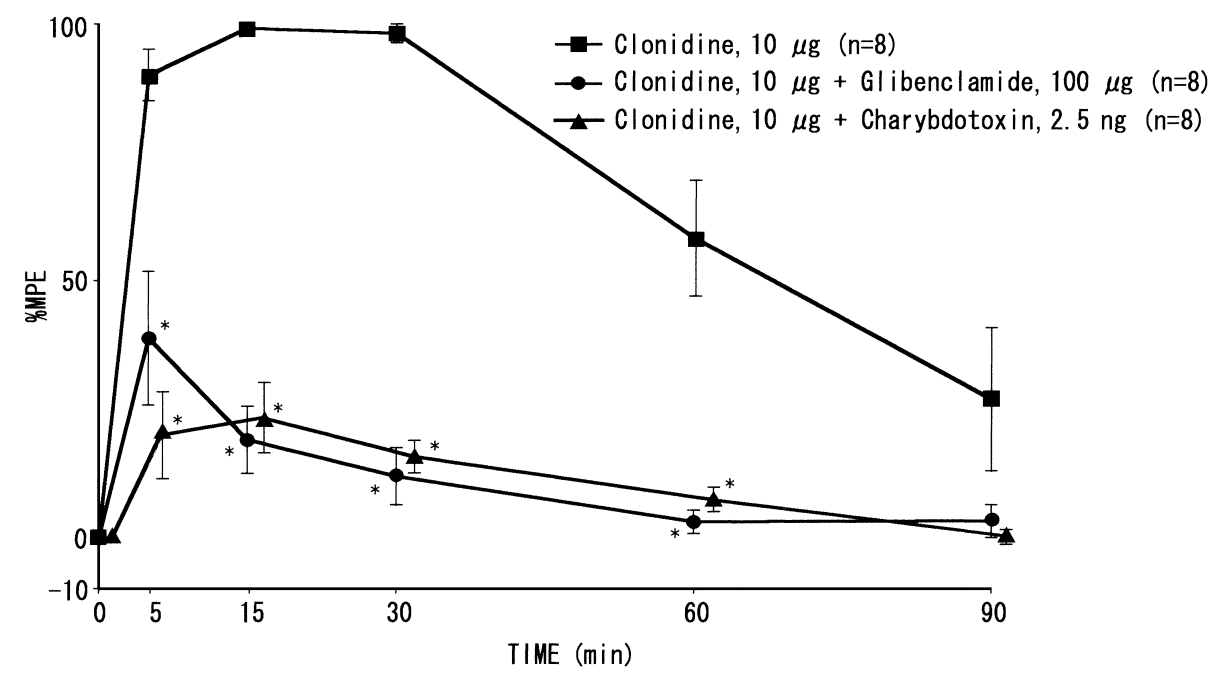

Fig. 4. Effects of pretreatment administrations of glibenclamide $(100 \mu \mathrm{g})$ or charybdotoxin $(2.5 \mathrm{ng})$ before clonidine $(10 \mu \mathrm{g})$ administration on the rat tailflick latency. Intrathecal administrations of $10 \mu \mathrm{g}$ clonidine (high-dose) produced antinociceptive effects, and clonidine (high-dose, $10 \mu \mathrm{g}$ )-induced antinociception was partially blocked by both glibenclamide and charybdotoxin. Postadministration tail-flick latencies were expressed as a percentage of the maximum possible effect (\%MPE). Values are each the mean \pm S.E.M. of 8 rats. Statistical significance $(* P<0.05)$ was determined by comparison with the curve for $10 \mu \mathrm{g}$ clonidine (closed squares). 
Effects of $\mathrm{K}^{+}$channels on bethanechol-induced antinociception

Although spinal antinociception was not observed after single administration of $10 \mu \mathrm{g}$ of bethanechol (low-dose), an antinociceptive effect was elicited when nicorandil was concomitantly administered with low-dose bethanechol. The $\%$ MPE was significantly elevated to $88 \%$ and $46 \%$ at 5 and $15 \mathrm{~min}$ after administration, respectively $(P<0.05)$. The tail-flick latency returned to the baseline at $90 \mathrm{~min}$ after concomitant drug administration (Fig. 5).

Spinal antinociception was observed in single administration of $40 \mu \mathrm{g}$ of bethanechol (high-dose), and it was partially antagonized by pretreatment with $100 \mu \mathrm{g}$ of glibenclamide. The \%MPE was significantly $(P<0.05)$ suppressed from $100 \%$ to $30 \%$, from $98 \%$ to $19 \%$, from $82 \%$ to $13 \%$ and from $23 \%$ to $1 \%$ at $5,15,30$ and 60 min after administration of high-dose bethanechol, respectively (Fig. 6).

In a similar manner, antinociception by high-dose cloni- dine was partially antagonized by pretreatment with $2.5 \mathrm{ng}$ of charybdotoxin. The \%MPE was significantly $(P<0.05)$ decreased from $100 \%$ to $47 \%$, from $98 \%$ to $22 \%$, from $82 \%$ to $1 \%$ and from $23 \%$ to $0 \%$ at $5,15,30$ and $60 \mathrm{~min}$ after administration of high-dose bethanechol, respectively (Fig. 6).

\section{Motor activity and histopathological analysis}

With regard to motor activities, fentanyl, clonidine, bethanechol, nicorandil, glibenclamide and charybdotoxin did not affect the animals at any of the doses tested (data not shown).

Also, no histological abnormality was observed in lumbar enlargement of the spinal cord where the tip of catheter was positioned (data not shown).

\section{DISCUSSION}

The present findings demonstrated that in i.t. administra-

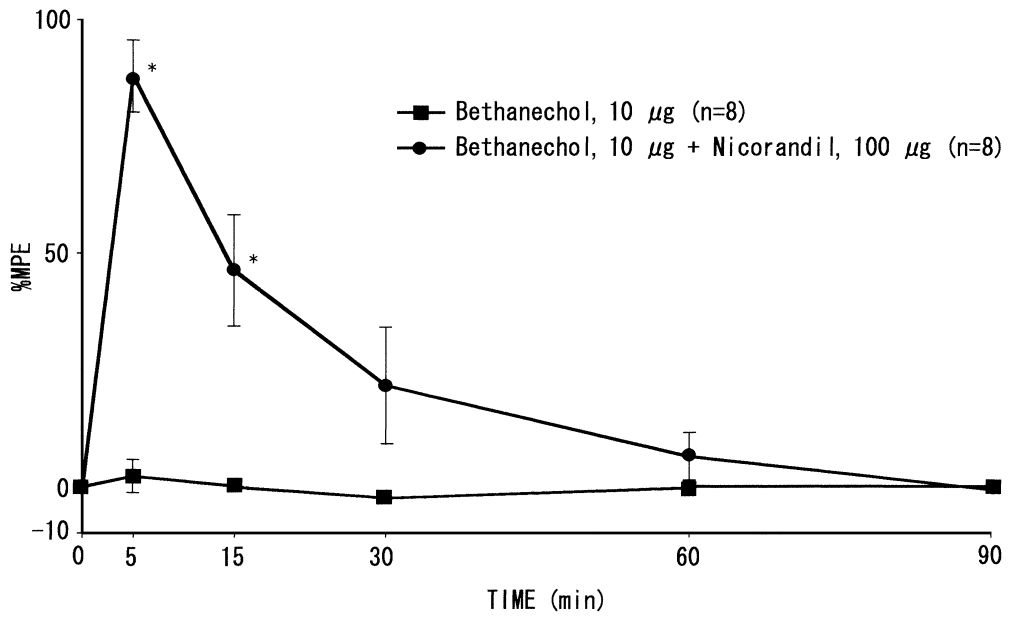

Fig. 5. Effects of concomitant administrations of bethanechol $(10 \mu \mathrm{g})$ and nicorandil $(100 \mu \mathrm{g})$ on the rat tail-flick latency. Although single intrathecal administrations of bethanechol (low-dose, $10 \mu \mathrm{g}$ ) did not affect the thermonociceptive response, significant antinociceptive effects were established with concomitant administrations of $10 \mu \mathrm{g}$ bethanechol (low-dose) and nicorandil. Post-administration tail-flick latencies were expressed as a percentage of the maximum possible effect (\%MPE). Values are each the mean \pm S.E.M. of 8 rats. Statistical significance $(* P<0.05)$ was determined by comparison with the curve for $10 \mu \mathrm{g}$ bethanechol (closed squares).

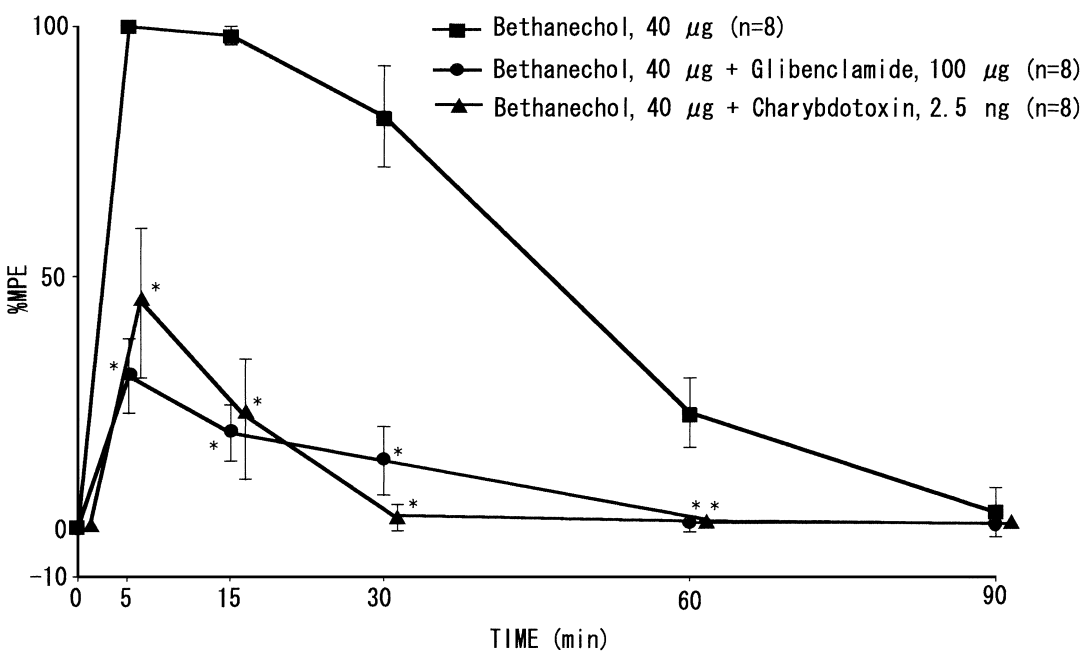

Fig. 6. Effects of pretreatment administrations of glibenclamide $(100 \mu \mathrm{g})$ or charybdotoxin $(2.5 \mathrm{ng})$ before bethanechol $(40 \mu \mathrm{g})$ administration on the rat tail-flick latency. Intrathecal administrations of $40 \mu \mathrm{g}$ bethanechol (high-dose) administration produced antinociceptive effects, and bethanechol (high-dose, $40 \mu \mathrm{g}$ )-induced antinociception was partially blocked by both glibenclamide and charybdotoxin. Post-administration tail-flick latencies were expressed as a percentage of the maximum possible effect (\%MPE). Values are each the mean \pm S.E.M. of 8 rats. Statistical significance $\left({ }^{*} P<0.05\right)$ was determined by comparison with the curve for $40 \mu \mathrm{g}$ bethanechol (closed squares). 
tion of the $\mathrm{K}^{+}$channel openers nicorandil alone exerted no influence on the tail-flick latency. However, concomitant administrations of antinociceptively inactive doses of fentanyl, clonidine and bethanechol with nicorandil elicited significant suppression of the thermonociceptive response in rats. Also, each antinociception induced by fentanyl, clonidine and bethanechol was partially antagonized by both the $\mathrm{K}_{\text {ATP }}^{+}$channel blocker glibenclamide and the $\mathrm{Ca}^{2+}$ activated $\mathrm{K}^{+}$channel blocker charybdotoxin. These findings showed that activation of the $\mathrm{K}^{+}$channel might modulate the antinociceptive effects of fentanyl, clonidine and bethanechol.

\section{Effects of $\mathrm{K}^{+}$channel openers on spinal antinociception}

It has been documented that the $\mathrm{K}^{+}$channel influences various neuronal pain processes and that the opening of $\mathrm{K}^{+}$channel in the cell membrane plays an important role in pain modulation. $\mathrm{K}^{+}$channels of the inwardly rectifying type are activated directly or indirectly by many receptors for neurotransmitters and neuropeptides. The distribution of opioid, adrenergic, or muscarinic receptors determines the neuronal pain processes evoked by their activating neurotransmitters. Opioid, $\alpha_{2}$ adrenergic, muscarinic, dopaminergic, adenosine and most of serotonin receptors are G-protein-coupled receptors that activate $\mathrm{K}^{+}$channels (11). The G-protein-coupled receptors can activate intracellular effectors and second messengers such as $\mathrm{Ca}^{2+}$.

The principal question is whether nicorandil $\left(\mathrm{K}_{\mathrm{ATP}}^{+}\right.$ channel opener) exerts antinociceptive effects by itself. In this experiment, none of the single administrations of 100 or $200 \mu \mathrm{g}$ of nicorandil per se produced any antinociceptive effect. Another report demonstrated that epidural nicorandil alone showed no antinociceptive effects, using the tail flick test in rats (18). In contrast, $\mathrm{K}^{+}$channel openers, such as cromakalim (19), diazoxide, minoxidil and lemakalim (17), elicit antinociceptive effects as measured in the tailflick test in mice. Although these findings differ from our results, it is possible that $\mathrm{K}^{+}$channel openers produced an antinociceptive effect via inhibitory postsynaptic potentials by opening the neuronal $\mathrm{K}^{+}$channels. Possibly one factor that determines whether or not $\mathrm{K}^{+}$channel openers per se produce antinociceptive effects may be the administered dosage or differences in species.

\section{Effects of $\mathrm{K}^{+}$channels on fentanyl-induced antinociception}

In this study, concomitant administrations of antinociceptively inactive doses of fentanyl with nicorandil elicited significant suppressions of the thermonociceptive response. $\mathrm{K}_{\text {ATP }}^{+}$channel openers, such as nicorandil and levcromakalim, potentiate the morphine-induced antinociceptive effect (18). Furthermore, cromakalim enhances the antinociceptive effects induced by morphine, buprenorphine and methadone $(19,20)$. Opioids can inhibit $\mathrm{Ca}^{2+}$ influx through the receptor-operated $\mathrm{Ca}^{2+}$ channels in neuronal cells and inhibit neurotransmitter release to eventually lower the content of $\mathrm{Ca}^{2+}$ in neurons, resulting in the eliciting of analgesia. In addition to the action of $\mathrm{Ca}^{2+}$ efflux, opioids lead to the opening of $\mathrm{K}^{+}$channels and neuronal hyperpolarization. Therefore, additional direct opening of the $\mathrm{K}^{+}$channels by nicorandil further potentiates the neuronal hyperpolarization and can elicit the analgesic effects of $\mu$-opioid. The modulation of $\mathrm{K}^{+}$may be very important in the mechanism of the interaction of opioids with intracellular $\mathrm{Ca}^{2+}$. Simultaneous activation of a common ion channel within individual neurons may facilitate the effector mechanism in multiple ways. In contrast, cromakalim does not modify the antinociceptions elicited by fentanyl and levorphanol (20). Possible hypotheses for these discrepancies, particularly between fentanyl and morphine, may be enumerated as follows: 1) $\mu_{1}$ - and $\mu_{2-}$ opioid receptors are coupled to $\mathrm{K}_{\text {ATP }}^{+}$channels differentially; 2) fentanyl-like and morphine-like drugs may act on $\mu$ opioid receptors with similar ligand-binding properties, but coupled to different transducer proteins and effector mechanisms; and 3) $\mu$-opioid agonists also show differences in their intrinsic activities (20). A second question that this study was designed to answer is whether the antinociceptive effect of opioids is antagonized by $\mathrm{K}^{+}$channel blockers. The antinociceptive effects induced by morphine are antagonized dose-dependently by glibenclamide, whereas other classes of $\mathrm{K}^{+}$channel families, such as tetraethylammonium bromide and quinine hydrochloride, do not affect the antinociception of opioids $(21,22)$. Subsequently, the antinociceptive effects of several $\mu$-opioid receptor agonists, such as morphine $(19,20,23-30)$, levorphanol (26), methadone $(20,26)$, buprenorphine (20), fentanyl (18) and apomorphine (30), are antagonized by $\mathrm{K}_{\text {ATP }}^{+}$channel blockers such as glibenclamide and gliqudone. In our study, the antinociception induced by fentanyl was partially antagonized by glibenclamide, implying that $\mathrm{K}_{\text {ATP }}^{+}$channels may play an important role in the antinociceptive effects of fentanyl. In contrast, glibenclamide does not produce a shift in the dose-response curves of fentanyl, alfentanil, carfentanil, sufentanil or $\beta$-endorphin (26). Further reports have demonstrated that gliquidone does not modify the antinociceptive effects of fentanyl and levorphanol (20). Thus, antagonization induced by $\mathrm{K}_{\text {ATP }}^{+}$channel blockers against antinociceptive effects of $\mu$-opioid agonists is considered to be drug-dependent. The three hypotheses mentioned above may account for these differences.

There are fewer reports concerning $\mathrm{Ca}^{2+}$-activated $\mathrm{K}^{+}$ channels than those on $\mathrm{K}^{+}{ }_{\text {ATP }}$ channels in antinociception in the spinal cord $(17,31) . \mathrm{Ca}^{2+}$-activated $\mathrm{K}^{+}$channels are structurally similar to voltage-gated $\mathrm{K}^{+}$channels and the open probability is also governed by intracellular $\mathrm{Ca}^{2+}$ concentration. Our results show that charybdotoxin 
( $2.5 \mathrm{ng} /$ rat, i.t.) inhibited the antinociceptive effect induced by fentanyl $(2.5 \mu \mathrm{g} / \mathrm{rat}$, i.t.). The morphine-induced antinociceptive effects $(2 \mu \mathrm{g} /$ mouse $)$ are partially blocked by apamine (10 ng/mouse, i.t.), but not charybdotoxin (250 pg/mouse, i.t.) (17). The dosage of charybdotoxin, differences in species (rat vs mouse) or drugs (morphine vs fentanyl) might have contributed to these discrepancies. Nevertheless, this remains to be confirmed by further investigations.

\section{Effects of $\mathrm{K}^{+}$channels on clonidine-induced antinocicep- tion}

Concomitant administrations of antinociceptively inactive doses of clonidine with nicorandil elicited significant suppression of the thermonociceptive response. Clonidine, which influences $\alpha_{2}$ adrenoceptors in the spinal cord directly, opens $\mathrm{K}^{+}$channels by coupling with G-proteins and facilitates the efflux of $\mathrm{K}^{+}$to the extracellular space to induce cell hyperpolarization before neurotransmitter release at the presynaptic membrane (32). Transmission of a noxious stimulus to the postsynaptic membrane is consequently suppressed. The $\mathrm{K}_{\text {ATP }}^{+}$channel openers, including cromakalim, minoxidil, pinacidil, diazoxide, nicorandil and levcromakalim, enhance the antinociceptive effects induced by $\alpha_{2}$ adrenergic agonists such as clonidine, guanabentz and dexmedetomidine $(18,27,31)$. Similar to the interaction mechanisms of opioids and $\mathrm{K}^{+}$channel openers, the interaction of clonidine and $\mathrm{K}^{+}$channel is probably not direct, but rather may occur via simultaneous activation of a common second messenger within individual neurons.

As with fentanyl, there is a question of whether the antinociceptive effect of clonidine is antagonized by $\mathrm{K}^{+}$ channel blockers. The antinociception induced by clonidine was partially antagonized by both glibenclamide and charybdotoxin. The $\mathrm{K}^{+}{ }_{\text {ATP }}$ channel blockers glibenclamide and gliquidone antagonize the antinociception induced by $\alpha_{2}$ adrenergic agonists such as clonidine, tizanidine, guanabentz and dexmedetomidine $(18,26,27,31)$. These reports showed that both $\mathrm{K}^{+}{ }_{\text {ATP }}$ channels and $\mathrm{Ca}^{2+}$-activated $\mathrm{K}^{+}$ channels are associated with antinociceptions induced by clonidine. It is highly possible that $\mathrm{K}^{+}$channels are associated with antinociceptive effects induced by $\alpha_{2}$ adrenergic agonists similar to those of opioids, although limited information is available on the interaction between adrenergic agonists and $\mathrm{K}^{+}$channels.

\section{Effects of $\mathrm{K}^{+}$channels on bethanechol-induced antinoci- ception}

Our results demonstrated that concomitant administrations of antinociceptively inactive doses of bethanechol with nicorandil elicited significant suppression of the thermonociceptive response at the spinal cord level of rats.
Muscarinic agonists, such as bethanechol and carbachol, facilitate the release of GABA through the presynaptic mechanisms in the spinal cord. Both glibenclamide and charybdotoxin antagonized partially the antinociception induced by bethanechol. In i.t. administration, the antinociceptive effects produced by carbachol were blocked dose-dependently by atropine, naloxone and glibenclamide, and the antinociceptive effect produced by morphine would be blocked dose-dependently by glibenclamide, but not by atropine (29). These results suggest that the antinociceptive effect produced by muscarinic agonists might be mediated by opioids and $\mathrm{K}_{\text {ATP }}^{+}$channels.

To our knowledge, this is the first report investigating the interaction of muscarinic agonists together with $\mathrm{K}^{+}$channel openers and $\mathrm{Ca}^{2+}$ activated $\mathrm{K}^{+}$channel blockers.

It has been shown that spinal antinociceptive effects can be induced when $\mathrm{K}^{+}$channel openers are administered in combination with an antinociceptively inactive dosage (low-dose) of drugs possessing different mechanisms of action. Furthermore, $\mathrm{K}^{+}$channel blockers antagonized the spinal antinociceptive effects induced by other high-dose drugs. In clinical situations, there are some concerns about various side-effects when single drugs are administered at high dosages to elicit effective analgesic action. For these reasons, investigations of low-dose combination therapies with different mechanisms of drug action to induce effective analgesic action should be valuable to reduce adverse effects. Combined administrations of clonidine and morphine (33), clonidine and neostigmine (34), as well as morphine and neostigmine (35), into the intrathecal or epidural space have produced effective analgesia with fewer adverse events. The promising results of our present experiments suggest that i.t. administrations of fentanyl, clonidine and bethanechol with $\mathrm{K}^{+}$channel openers may be a potentially useful alternative for controlling and managing analgesic responses in clinical application.

In summary, the $\mathrm{K}^{+}$channel opener nicorandil produced significant enhancement of the antinociceptive effects of fentanyl, clonidine and bethanechol in the rat spinal cord. In addition, the analgesic actions of fentanyl, clonidine and bethanechol were partially reversed by both $\mathrm{K}^{+}{ }_{\text {ATP }}$ channel and $\mathrm{Ca}^{2+}$-activated $\mathrm{K}^{+}$channel blockers. Consequently, $\mathrm{K}^{+}$ channels may play an important role as indirect modulators in the analgesic action of $\mu$-opioid, $\alpha_{2}$ adrenergic and muscarinic agonists.

Acknowledgments

I would like to express my gratitude to Drs. Kazuki Hatsuoka, Norio Tsuchiya and Katsutoshi Wakita for their technical advice and kind cooperation. A part of this study was presented at the 47th Annual Meeting of the Japan Society of Anesthesiology in Tokyo (April, 2000) and the 34th Annual Meeting of The Japan Society of Pain Clinicians in Tokyo (July, 2000). 


\section{REFERENCES}

1 Schultz JEJ, Hsu AK and Gross GJ: Morphine mimics the cardioprotective effect of ischemic preconditioning via a glibenclamide-sensitive mechanism in the rat heart. Circ Res 78, $1100-1104$ (1996)

2 Crystal GJ, Gurevicius J, Salem MR and Zhou X: Role of adenosine triphosphate-sensitive potassium channels in coronary vasodilatation by halothane, isoflurane, and enflurane. Anesthesiology 86, 448 - 458 (1997)

3 Ko SH, Lee SK, Han YJ, Choe H, Kwak YG, Chae SW and Cho KP: Blockade of myocardial ATP-sensitive potassium channels by ketamine. Anesthesiology 87, 68 - 74 (1997)

4 Olschewski A, Bräu ME, Olschewski H, Hempelmann G and Vogel W: ATP-dependent potassium channel in rat cardiomyocytes is blocked by lidocaine: possible impact on the antiarrhythmic action of lidocaine. Circulation 93, 656 - 659 (1996)

5 Garlid KD, Paucek P, Yarov-Yarovoy V, Murray HN, Darbenzio RB, D'Alonzo AJ, Lodge NJ, Smith MA and Grover GJ: Cardioprotective effect of diazoxide and its interaction with mitochondorial ATP-sensitive $\mathrm{K}^{+}$channels: possible mechanism of cardioprotection. Circ Res 81, 1072 - 1082 (1997)

6 Inagaki N, Gonoi T, Clement JP, Namba N, Inazawa J, Gonzalez G, Aguilar-Bryan L, Seino S and Bryan J: Reconstitution of $\mathrm{I}_{\mathrm{KATP}}$ : an inward rectifier subunit plus the sulfonylurea receptor. Science 270, 1166 - 1170 (1995)

7 Morley $\mathrm{J}$ : $\mathrm{K}^{+}$channel openers and suppression of airway hyperreactivity. Trends Pharmacol Sci 15, 463 - 468 (1994)

8 Pang CY, Yang RZ, Zhong A, Xu N, Boyd B and Forrest CR: Acute ischaemic preconditioning protects against skeletal muscle infarction in the pig. Cardiovasc Res 29, 782-788 (1995)

9 Quast U, Guillon JM and Cavero I: Cellular pharmacology of potassium channel openers in vascular smooth muscle. Cardiovasc Res 28, 805 - 810 (1994)

10 Aronson JK: Potassium channels in nervous tissue. Biochem Pharmacol 43, 11 - 14 (1992)

11 Yost CS: Potassium channels: basic aspects, functional roles, and medical significance. Anesthesiology 90, 1186-1203 (1999)

12 Amoroso S, Schmid-Antomarchi H, Fosset M and Lazdunski M: Glucose, sulfonylureas, and neurotransmitter release: role of ATP-sensitive $\mathrm{K}^{+}$channel. Science 247, 852 - 854 (1990)

13 Mourre C, Widmann C and Lazdunski M: Specific hippocampal lesions indicate the presence of sulfonylurea binding sites associated to ATP-sensitive $\mathrm{K}^{+}$channels both post-synaptically and on mossy fibers. Brain Res 540, 340 - 344 (1991)

14 Kersten JR, Gross GJ, Pagel PS and Warltier DC: Activation of adenosine triphosphate-regulated potassium channels: mediation of cellular and organ protection. Anesthesiology 88, 495- 513 (1998)

15 Yamashita S, Park JB, Ryu PD, Inukai $H$, Tanifuji $M$ and Murase K: Possible presence of the ATP-sensitive $\mathrm{K}^{+}$channel in isolated spinal dorsal horn neurons of the rat. Neurosci Lett 170, 208 - 212 (1994)

16 Yaksh TL and Rudy TA: Chronic catheterization of the spinal subarachnoid space. Physiol Behav 17, 1031 - 1036 (1976)

17 Welch SP and Dunlow LD: Antinociceptive activity of intrathecally administered potassium channel openers and opioid agonists: a common mechanism of action? J Pharmacol Exp
Ther 267, 390 - 399 (1993)

18 Asano T, Dohi S and Iida H: Antinociceptive action of epidural $\mathrm{K}^{+}{ }_{\text {ATP }}$ channel openers via interaction with morphine and an $\alpha_{2}$ adrenergic agonist in rats. Anesth Analg 90, 1146 - 1151 (2000)

19 Narita M, Takamori K, Kawashima N, Funada M, Kamei J, Suzuki T, Misawa M and Nagase H: Activation of central ATPsensitive potassium channels produces the antinociception and spinal noradrenaline turnover-enhancing effect in mice. Psychopharmacology (Berl) 113, 11 - 14 (1993)

20 Ocaña M, Pozo ED, Barrios M and Baeyens JM: Subgroups among $\mu$-opioid receptor agonists distinguished by ATP-sensitive $\mathrm{K}^{+}$channel-acting drugs. Br J Pharmacol 114, 1296- 1302 (1995)

21 Ocaña M, Pozo ED, Barrios M, Robles LI and Baeyens JM: An ATP-dependent potassium channel blocker antagonizes morphine analgesia. Eur J Pharmacol 186, 377 - 378 (1990)

22 Wild KD, Vanderah T, Mosberg HI and Porreca F: Opioid $\delta$ receptor subtypes are associated with different potassium channels. Eur J Pharmacol 193, 135 - 136 (1991)

23 Narita M, Suzuki T, Misawa M, Nagase H, Nabeshima A, Ashizawa T, Ozawa H, Saito T and Takahata N: Role of central ATP-sensitive potassium channels in the analgesic effect and spinal noradrenaline turnover-enhancing effect of intracerebroventricularly injected morphine in mice. Brain Res 596, $209-$ 214 (1992)

24 Ocaña M, Pozo ED and Baeyens JM: ATP-dependent $\mathrm{K}^{+}$channel blockers antagonize morphine- but not U-504,88H-induced antinociception. Eur J Pharmacol 230, 203 - 207 (1993)

25 Welch SP, Thomas C and Patrick G: Modulation of cannabinoidinduced antinociception after intracerebroventricular versus intrathecal administration to mice: possible mechanisms for interaction with morphine. J Pharmacol Exp Ther 272, 310 - 321 (1995)

26 Raffa RB and Martinez RP: The 'glibenclamide-shift' of centrally-acting antinociceptive agents in mice. Brain Res 677, 277 - 282 (1995)

27 Ocaña M, Barrios M and Baeyens JM: Cromakalim differentially enhances antinociception induced by agonists of $\mathrm{alpha}_{2}$ adrenoceptors, $\gamma$-aminobutyric $\operatorname{acid}_{\mathrm{B}}$, mu and kappa opioid receptors. J Pharmacol Exp Ther 276, 1136 - 1142 (1996)

28 Yang SW, Kang YM, Guo YQ and Qiao JT: ATP-sensitive potassium channels mediate norepinephrine- and morphineinduced antinociception at the spinal cord level. Int J Neurosci 93, 217 - 223 (1998)

29 Kang YM, Zhang C and Qiao JT: Involvement of endogenous opioids and ATP-sensitive potassium channels in the mediation of carbachol-induced antinociception at the spinal level: a behavioral study in rats. Brain Res 761, 342 - 346 (1997)

30 Kang YM, Hu WM and Qiao JT: Endogenous opioids and ATP-sensitive potassium channels are involved in the mediation of apomorphine-induced antinociception at the spinal level: a behavioral study in rats. Brain Res Bull 46, 225 - 228 (1998)

31 Galeotti N, Ghelardini C, Vinci MC and Bartolini A: Role of potassium channels in the antinociception induced by agonists of $\alpha_{2}$-adrenoceptors. Br J Pharmacol 126, 1214 - 1220 (1999)

32 Holz GG, Kream RM, Spiegel A and Dunlap K: G proteins couple $\alpha$-adrenergic and $\mathrm{GABA}_{\mathrm{B}}$ receptors to inhibition of peptide secretion from peripheral sensory neurons. J Neurosci 9, 657 - 666 (1989)

33 Motsch J, Gräber E and Ludwig K: Addition of clonidine 
enhances postoperative analgesia from epidural morphine: a double-blind study. Anesthesiology 73, 1067 - 1073 (1990)

34 Hood DD, Mallak KA, Eisenach JC and Tong C: Interaction between intrathecal neostigmine and epidural clonidine in human volunteers. Anesthesiology 85, 315 - 325 (1996)
35 Chung CJ, Kim JS, Park HS and Chin YJ: The efficacy of intrathecal neostigmine, intrathecal morphine, and their combination for post-cesarean section analgesia. Anesth Analg 87, $341-346$ (1998) 